\title{
Pulmonary Clearance of Staphylococcus aureus in Mutant Mice with Some Hereditary Alterations Resembling Cystic Fibrosis
}

\author{
OMAR H. PIVETTA, ${ }^{(33)}$ DANIEL O. SORDELLI, AND MABEL L. LABAL \\ Centro de Genética Médica, Buenos Aires, Argentina
}

\section{Summary}

Pulmonary clearance for Staphylococcus aureus has been examined in two inbred strains of mice with some hereditary alterations resembling cystic fibrosis (CF). These mice were mice with abnormal electrolyte metabolism (DBA/2J-cri), mice with spontaneous pneumonitis (C57 BL/6J-bg ${ }^{\mathrm{J}}$ ), and mice without any $\mathrm{CF}$-like alterations (BALB/c).

The methods used to produce pulmonary infection were essentially those of Laurenzi and associates adapted as needed for mutant mice. The animals mentioned above were exposed to a finely divided aerosol suspension of a coagulase-positive strain of $S$. aureus in phosphate buffer.

Immediately after the exposure, half of the animals were killed, and the remaining half were killed $4 \mathrm{hr}$ later. In each experimental unit the mice killed immediately after the exposure were as similar as possible to the mice killed $4 \mathrm{hr}$ later with respect to genotype, age, and sex; some were siblings.

The uncleared bacteria (UBR) in $4 \mathrm{hr}$ were 0.20 for the mice without any CF-like alterations (BALB/c) and the C57BL/6J$b g, b g / b g$ genotypes; 0.28 for C57BL/6J-bg, +/? genotypes; 0.50 for the $\mathrm{DBA} / 2 \mathrm{~J}-c r i,+/$ ? genotypes; and 0.56 for cri/cri mice.

The number of viable staphylococci found immediately after the aerosol exposure $(\mathrm{Co})$ in the $\mathrm{C57} \mathrm{BL} / 6 \mathrm{~J}-b \mathrm{~g}$ strain is significantly lower than the Co of the BALB/c $(P<0.05)$ and DBA/ $2 \mathrm{~J}$-cri strain $(P<0.01)$. The latter two did not differ from each other.

There was no sex difference with respect to the UBR and Co data. The DBA/2J-cri strain of mice, where the cri mutation first appeared, has a decreased capacity for clearance of $S$. aureus by the lung. Together with the other CF-like alterations of the cri mutation, namely failure for the reabsorption of $\mathrm{Na}^{+}$ by the parotid duct, high level of $\mathrm{Na}^{+}$in the fur, and $\mathrm{CF}$ abnormal serum factor activity in the serum of cri/cri mice, we suggest that the cribriform degeneration mouse mutant may provide a potential animal model for studying $\mathrm{CF}$.

\section{Speculation}

The finding of a mouse mutation with electrolyte alterations and CF-like abnormal serum activity, similar to the activity found in CF children, in an inbred strain of mice with a decreased bacterial clearance by the lungs, makes these mice very useful for CF studies.

Rarely does a CF patient escape pulmonary involvement and most patients succumb to it (28). Since $\mathrm{CF}$ is a generalized metabolic disorder, different hypothesis have been advanced to explain this condition. Traditionally it had been thought that an initial accumulation of mucus in the lung predisposes to pulmonary infection, which then leads to the production of more mucus and a more obstructive lung disease (3). It was suggested than the CF environment of the mucus prevents contact between alveolar macrophages and bacteria, this being an example of a host producing its own local pollutant (25).

Green's observations (8) suggest that the bactericidal action of the bronchopulmonary tree is due primarily to the phagocytic activity of alveolar macrophages, and that the action of the mucociliary stream in relation to bacterial clearance may be associated largely with transport in the lung of phagocytes containing material of bacteria origin. The crucial link between the function of alveolar macrophages and mucociliary clearance is not well known. Therefore, the other mechanisms of clearance must include several different functions.

The present study is a part of our effort to develop an animal model for cystic fibrosis and was designed to determine quantitatively whether in inbred mice, different mutations with some $\mathrm{CF}$ like conditions have an altered pulmonary clearance for $S$. aureus.

Our work is related to the finding that staphylococci were the main organisms present in the tracheal broncheal tree of CF patients before the advent of antibiotics $(4,15)$, and to the work of Lawson, who believes that the event leading to pulmonary parenchymal damage in $\mathrm{CF}$ begins with the staphylococcal infection at some point in the patient's life (22). In addition, it is known that the pulmonary macrophage system is susceptible to a variety of metabolic situations such as hypoxia, cold stress, ethanol intoxication, acidosis, cortisol, tobacco smoking, and many others $(9,10,18,21)$.

\section{MATERIALS AND METHODS}

\section{MICE}

With the exception of BALB/c strain, the choice of strains of mice and genotypes was predicated on the possibility that they might furnish an animal model for cystic fibrosis. During the last 6 years, we have been trying to find a mouse mutation with alterations resembling human CF. One of the most interesting mutations detected was cribriform degeneration (cri) in the $\mathrm{DBA} / 2 \mathrm{~J}$ inbred strain (11). In the homozygous state this mutation produces a defect in the $\mathrm{Na}^{+}$transport by the parotid gland (17), an excess of $\mathrm{Na}^{+}$in hair, salt preference, normal adrenal and kidney function, normal $\mathrm{Na}^{+}$levels in the plasma, normal $\mathrm{Na}^{+}(11)$ and $\mathrm{K}^{+}$levels in the red blood cells, and CF-abnormal serum factor activity (26). Similar defects are seen in CF patients. The C57BL/6J-bg strain was assayed because the homozygotes develop a spontaneous pneumonitis (19).

Mice of all strains and genotypes were 21-30 days old on entry into the experiments. The animals had free access to water and a pelleted food.

\section{PREPARATION OF BACTERIAL SUSPENSION}

A coagulase-positive strain of $S$. aureus taken from a human patient with chronic lung disease was used. The infective bacte- 
rial suspension was obtained by inoculating $50 \mathrm{ml}$ tryptic soy broth (29) with an aliquot of culture and incubating it at $37^{\circ}$ in a shaker water bath for $18 \mathrm{hr}$. A portion of the culture was centrifuged and the pellet was resuspended in phosphate buffer,

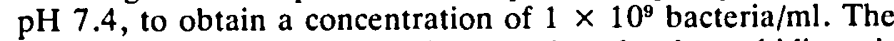
adjustment to this concentration was done by the turbidimetric method of comparison with a suspension in $\mathrm{BaSO}_{4}$.

\section{INFECTION}

The mice were infected by inhalation of the aerosol from a nebulization chamber which was made by the authors. The design is based on the experience of Lurie et al. (23), Middlebrook (24), and Laurenzi et al. (20). The inhalation chamber consists of a cylindrical glass chamber having an internal ringshaped wire cage, placed halfway between the top and the bottom. Two pairs of mice, taken at random, each belonged to different strains or genotypes, were exposed at the same time in each trial. In this way it was possible to circumvent huddling, to produce a uniform flow of the aerosol through the chamber, and to minimize the stress produced by immobilization (27). The small standard error of the UBR and Co data is an indication of the good reproducibility of this method and gives a measure of the possible limitations of this technique which compares in a single run only two groups of mice among five possible genotypes.

The chamber receives the infecting aerosol from the top, produced by a nebulizer which operates following the principle of the Venturi tube. Eight milliliters of the bacterial suspension are placed in the reservoir. A vacuum pump is connected to the chamber, producing an air flow of 4-4.5 liters $/ \mathrm{min}$. This air flow circulates the infecting aerosol through the system. Between the chamber and the vacuum pump three washing flasks are intercalated, the first one containing a sulfochromic solution, the second a saturated solution of $\mathrm{Na}_{2} \mathrm{CO}_{3}$, and the third flask remaining empty to retain bacteria which pass through the chamber.

Because of the pump's action, dry air flows into the chamber through an entrance placed between the nebulizer and the chamber itself, thereby drying the infecting droplets, which can reach a diameter smaller than $5 \mu \mathrm{m}$. The system operates at a negative pressure of approximately $8-10 \mathrm{~mm}$ water; thus the possible escape of contaminated material is avoided.

\section{GENERAL OPERATION}

To accustom the mice to the chamber, four mice were placed in the cage inside the nebulization chamber $30 \mathrm{~min}$ before beginning the aerosol circulation. After $30 \mathrm{~min}$ of exposure, the chamber was cleared by air flowing for $10 \mathrm{~min}$. Mice were killed at different times by cervical dislocation, and precautions were taken to prevent agonal aspiration of pharyrigeal contents. In each experimental unit, one mouse was killed immediately after the exposure and another $4 \mathrm{hr}$ later $(9,20)$. The total number of trials, which was dependent on the mutant mice availability, was 36 , two experimental units each day.

The entire lung tissue of each mouse was aseptically removed, and after washing tissue in sterile saline solution and sectioning the bronchi at the pulmonary hilum level, the lungs were weighed individually. They were then homogenized in a PotterElvehjem glass homogenizer. An aliquot of each homogenate, diluted in a sterile saline solution, was cultured quantitatively by a pour plate technique (30). With another aliquot, an isolation procedure in blood agar plates was carried out to detect the presence of possible contaminating agents. The plates were incubated at $37^{\circ}$ for $48 \mathrm{hr}$ and the colonies were counted and reported as colony forming units (CFU).

\section{DEFINITIONS AND STATISTICAL CONSIDERATIONS}

Uncleared bacteria ratio is the number of CFU per $g$ wet lung found $4 \mathrm{hr}$ after being nebulized, divided by specific bacterial count $(\mathrm{Co})$ in a sibling of the same genotype, age, and sex. Co is the number of CFU versus grams of wet lung found immediately after the aerosol exposure.

A variance analysis of UBR and Co data was carried out. Previously they were lineal and logarithmically transformed in order to get homoscedasticity. The variance homogeneity was proved by using Bartlett contrast (2); the correct adjustment to normal distribution was graphically checked, using rankits (7). We also tested for extreme anomalous data (5) in transformed groups, but it was not necessary to discard any one of them. Once homoscedasticity and normality had been obtained, a variance analysis was made with one criterion of classification.

\section{RESULTS}

\section{UNCLEARED BACTERIA RATIO (UBR)}

Statistical tests show a definite heterogeneity in the variances of each one of the studied groups; in particular, the variance of homozygotes for the cri gene of the DBA/2J-cri strain is approximately 20 times larger than the smallest variances of the remaining groups.

A previous analysis of logarithmic transformed data showed no sexual differences; the final statistical analysis was carried out by grouping the combined data for both sexes. The arithmetic means \pm standard errors obtained on UBR are detailed in Table 1.

A significant difference $(P<0.01)$ was found in UBR between the homozygotes for the $b g$ gene and $+/$ ? group of C57BL/6J-bg strain. There is no UBR statistical difference between homozygotes for the cri gene and the $+/$ ? group DBA/2Jcri strain. By means of a variance analysis for each strain, we can observe that DBA/2J-cri UBR without any genotype distinction is significantly larger $(P<0.01)$ than $\mathrm{BALB} / \mathrm{c}$ and $\mathrm{C} 57 \mathrm{BL} / 6 \mathrm{~J}-$ bg clearances, which are not significantly different.

Table 1. Uncleared bacteria ratio of Staphylococcus aureus in different mutations and inbred strains of mice with some cystic fibrosis-like alterations

\begin{tabular}{|c|c|c|c|}
\hline \multirow[b]{2}{*}{ Strain } & \multirow[b]{2}{*}{ Genotype } & \multicolumn{2}{|c|}{ Uncleared bacteria ratio' at $4 \mathrm{hr}$} \\
\hline & & Genotypes & Strains \\
\hline $\mathrm{BALB} / \mathrm{c}$ & $\mathbf{a} / \mathbf{a}$ & $0.20 \pm 0.01(13)^{2}$ & $0.20 \pm 0.01(13)$ \\
\hline $\mathrm{DBA} / 2 \mathrm{~J}-c r i$ & $+/ ?$ & $\underline{0.50 \pm 0.02(17)}$ & $0.53 \pm 0.02(30)$ \\
\hline $\mathrm{DBA} / 2 \mathrm{~J}-c r i$ & cri/cri & $0.56 \pm 0.04(13)$ & \\
\hline C57BL/6J-bg & $+1 ?$ & $\underline{0.28 \pm 0.01(16)}$ & $0.25 \pm 0.01(29)$ \\
\hline $\mathrm{C} 57 \mathrm{BL} / 6 \mathrm{~J}-b g$ & $b g / b g$ & $0.20 \pm 0.02(13)$ & \\
\hline
\end{tabular}

1 Number of colony-forming units at $4 \mathrm{hr} /$ number of colony-forming units at zero time.

$2 \bar{X} \pm$ SE. Number of experimental units is shown within parentheses. 
SPECIFIC BACTERIAL COUNT (Co)

Arithmetic means corresponding to Co are detailed in Table 2. The statistical procedure for analyzing the Co data is identical with the one applied to the UBR data.

It can be seen that the Co of the C57BL/6J-bg strain is significantly different from the Co of the BALB/c strain $(P<$ $0.05)$ and from the Co of the DBA/2J-cri strain $(P<0.01)$. The latter two did not differ. There were also no differences between the sexes of the same genotype or between genotypes of the same strain. All the data were obtained by the double blind procedure.

\section{PATHOGENIC CAPACITY OF $S$. AUREUS}

To determine the pathogenic capacity of $S$. aureus by airborne way, different lots of animals were nebulized in order to verify any signs of disease. All the genotypes in lots of six mice each were exposed to infecting aerosol in conditions similar to the ones applied in all the experiments.

Afterwards, and for a period of 12 days, the general health and behavior of the mice were checked. At the end of this time, the mice were killed to establish whether or not there were viable $S$. aureus in the lungs. BALB/c, C57BL/6J-bg (bg/bg and $+/$ ?), and DBA/2J-cri mice $(+/$ ? ) did not show abnormal behavior or clinical signs of lung disease. Mice homozygous for the $c r i$ gene (cri/cri) became very sick $48 \mathrm{hr}$ after the nebulization, showing adynamia and a marked decrease in respiratory frequency and depth of breathing.

It is emphasized that these animals were killed during the first $48 \mathrm{hr}$ to avoid possible descending contaminations in the lower respiratory tract, as they develop very quickly once the animal is dead. Nevertheless, viable $S$. aureus were not found in these mice, excepting one animal which, because of its moribund condition, was killed $6 \mathrm{hr}$ after the nebulization. In this animal there were $10^{5}$ staphylococci/g wet lung tissue.

\section{COMPLEMENTARY STUDIES}

The deposition level of infecting particles is closely dependent on their aerodynamic dimensions (1). To have an idea of these dimensions, their sizes were semiquantified. Nebulizations were made with nonviable autoclaved $S$. aureus suspensions on a reticular siliconized surface. They were measured under the microscope, in a wet atmosphere, with a measuring ocular lens. Ninety percent of the particles were smaller than $5 \mu \mathrm{m}$ in diameter; $9 \%$ ranged between 5 and $10 \mu \mathrm{m}$. With these dimensions it is most likely that the infecting particles reached the lung alveoli of the experimental mice.

For this research 200 animals were examined. Only 2 showed bacterial infection preexisting at a lung level. They were sibling DBA/2J-cri mice (cri/cri genotype) that had come from the same cage and were contaminated with Acinetobacter sp. One had $10^{6}$ and the other $10^{4}$ microorganisms/g wet lung tissue. None of the lungs studied showed macroscopic morphologic alterations.

\section{DISCUSSION}

There is evidence that a mechanism operating in situ is responsible for early pulmonary clearance of bacteria settled, in greater part, in the upper respiratory tract. The clearance which accounts for most of the antibacterial activity appears to be mediated primarily by the pulmonary macrophages and is relatively independent of the function of the mucociliary apparatus. Therefore, it may be that a failure in this system of defense is one of the causes for the development of infective lung disease (6).

In a search for an animal model useful for CF study, the chronic infective pathology of the lungs of CF patients must be taken into account. For this reason, pulmonary clearance of bacteria was checked in two strains of mice that are carriers of a gene which, in the homozygous condition, recalls some of individual symptoms of $\mathrm{CF}$.

Many studies have reported the high incidence of coagulasepositive staphylococci in the upper respiratory tract and pulmonary secretions of children with $\operatorname{CF}(13,14,16)$.

Our use of bacteria that are nonpathogenic for animals under the conditions of the experiments permitted an analysis of changes in the host defenses without the intervention of the cellular and humoral alterations accompanying disease processes. Our choice, therefore, was an $S$. aureus strain nonpathogenic for the mouse under our conditions, not even individuals homozygous for the cri gene, who always die prematurly during an assay of the pathogenic power of a bacterial strain. It was determined that the condition of these mice when killed for study was not caused by pulmonary staphylococcus infection.

Homozygous individuals for the $b g$ gene of the C57BL/6J-bg strain have a more effective clearance than $+/$ ? individuals of the same strain. This is a phenomenon we are not yet able to explain. The phenotypic expression of the $b g$ gene in homozygous individuals is a spontaneous pneumonitis. This should cause a decreased pulmonary clearance and not an improvement, as was seen in the present study. Nevertheless, it must be borne in mind that the mice used ranged in age between 3 and 5 weeks at the start of the experiments, and that pneumonitis appears after the 6 th month of life.

The most important finding is the DBA/2J-cri strain pulmonary clearance; this happens to be significantly smaller for the cri/cri and $+/$ ? individuals, as compared to the mice of the other two strains studied.

With this study we cannot rule out the possibility that these mice would be more susceptible to systemic infections of this particular strain of bacteria. It is very well known that the alveolar macrophages mediate the cellular response to airborne challenge, whereas the polymorphonuclear leukocytes defend the lung from circulating bacteria (12).

The observed dispersion in UBR values in this strain is important. It is justified in individuals homozygous for the cri gene because the general condition of these mice was not always comparable when they were nebulized. They were in different stages of the cri phenotypical expression, i.e., there was a progressive decrease of vital functions and, finally, death.

Table 2. Numbers of viable staphylococci remaining in mouse lungs at zero time after exposure to aerosols of bacteria (Co)

Staphylococci in lungs ${ }^{1}$ at zero time

\begin{tabular}{lccc} 
Strain & Genotype & Genotypes & Strains \\
\cline { 3 - 4 } BALB/c & a/a & $11.40 \pm 1.14(13)^{2}$ & $11.40 \pm 1.14(13)$ \\
DBA/2J-cri & $+/ ?$ & $\frac{15.70 \pm 1.61(17)}{12.89 \pm 2.30(13)}$ & $14.48 \pm 1.35(30)$ \\
DBA/2J-cri & $c r i / c r i$ & $7.94 \pm 0.73(16)$ & $8.33 \pm 0.48(29)$ \\
C57BL/6J-bg & $+/ ?$ & $8.82 \pm 0.65(13)$ & \\
C57BL/6J-bg & $b g / b g$ &
\end{tabular}

' Number of colony-forming units/g wet lung.

$2(\bar{X} \pm S E) \times 10^{5}(n)$. 
Among the $+/$ ? individuals of this strain there is a large dispersion but it is not so marked as the one found in cri homozygotes. The distribution of values for a DBA/2J-cri $(+/$ ? genotype) sample of mice happened to be statistically unimodal, without excluding the possibility that there are two different populations, one composed of $+1+$ individuals and the other of heterozygous $+/ c r i$, both with very close UBR values.

It is of interest that the Co is not different between two strains such as BALB/c and DBA/2J-cri, which have different UBR. Consequently, it can be deduced that the physiologic factors involved in bacterial inhalation do not differ importantly between these two strains. The difference, however, is remarkable when comparing the $\mathrm{BALB} / \mathrm{c}$ or $\mathrm{DBA} / 2 \mathrm{~J}-\mathrm{cri}$ strains with C57BL/6J-bg, for the latter will show a lower Co level.

We plan to verify whether the observed deficiency in the pulmonary clearance of bacteria is the result of a primary failure of the phagocytic alveolar cells or of a disturbance which develops in the environment of these cells, preventing an effective clearing action.

The deficient $\mathrm{Na}^{+}$reabsorption in the parotid gland duct, the high electrolyte level in fur, the finding of inhibitory activity of ciliated movement in serum, and the deficiency in pulmonary clearance of bacteria, which may have or not a pathogenic expression, are present both in cri/cri homozygotes and in human beings with $C F$.

All these findings must be taken into account in order to evaluate the possibility of DBA/2J-cri homozygotes (cri/cri) serving as an animal model for studying $\mathrm{CF}$ in human beings.

\section{CONCLUSION}

Pulmonary clearance of $S$. aureus in different inbred strains of mice with some CF-like hereditary alterations has been examined. DBA/2J-cri mice homozygous and heterozygous for the $c r i$ gene show a decreased pulmonary clearance when compared to mice strain $\mathrm{C} 57 \mathrm{BL} / 6 \mathrm{~J}-b g$ and the $\mathrm{BALB} / \mathrm{c}$ unaffected strain. This is not dependent on the number of bacteria found immediately after bacterial aerosol exposure, regardless of the sex.

In addition, the cri/cri mice are characterized by a defect in the transport of $\mathrm{Na}^{+}$by the parotid gland, a high level of sodium in fur, and a CF abnormal serum factor activity.

Because of these findings, cri/cri mice present a very promising tool for CF studies.

\section{REFERENCES AND NOTES}

1. Andersen, A. A.: New sampler for the collection, sizing and enumeration of viable airborne particles. J. Bactiol., 76(5): 471 (1958).

2. Bartlett, M. S.: The use of transformations. Biometrics, 3: 39 (1947)

3. Di Sant'Agnese, P. A.: The lung as an organ of defense. Gap Conference Reports, National Cystic Fibrosis Research Foundation, Rougemont, North Carolina, November 1972 .

4. Di Sant'Agnese, P. A., and Anderson, D. H.: Celiac syndrome. IV. Chemotherapy in infections of the respiratory tract associated with cystic fibrosis of the pancreas. Amer. J. Dis. Child., 72: 17 (1946).

5. Dixon, N. J.: Analysis of extreme values: Annals of mathematical statistics. 21: 488 (1950).

6. Feigin, R. P., and Shearer, 'N. T.: Opportunistic infection in children. II. In the compromised host. J. Pediat., 87: 677 (1975).

7. Finney, D. J.: Probit Analysis, Ed. 3 (Cambridge University Press, Cambridge, 1971).
8. Green, G. M., and Kass, E. H.: The role of the alveolar macrophage in the clearance of bacteria from the lung. J. Exp. Med., 119: 167 (1964).

9. Green, G. M., and Kass, E. H.: Factors influencing the clearance of bacteria by the lung. J. Clin. Invest., 43: 769 (1964).

10. Green, G. M., and Kass, E. H.: The influence of bacterial species on pulmonary resistance to infection in mice subjected to hypoxia, cold stress and ethanolic intoxication. Brit. J. Exp. Path., 46: 360 (1965).

11. Green, M. C., Sidman, R. L., and Pivetta, O. H.: Cribriform degeneration (cri): A new recessive neurological mutation in the mouse. Science, 176: 800 (1972).

12. Harrow, E. M., Jakab, G. J., Brody, A. R., and Green, G. M.: The pulmonary response to a bacteremic challenge. Amer. Rev. Resp. Dis., 112: 7 (1975).

13. Hoff, G. E., and Høiby, N.: Staphylococcus aureus in cystic fibrosis: Antibiotic sensitivity and phage types during the latest decade. Investigations of the occurrence of protein $\mathrm{A}$ and some other properties of recently isolated strains in relation to the occurrence of precipitating antibodies. Acta Path. Microbiol. Scand., Sect. B, 83: 219 (1975).

14. Hoiby, N.: Epidemiological investigations of the respiratory tract bacteriology in patients with cystic fibrosis. Acta Path. Microbiol. Scand., Sect. B, 82: 541 (1974).

15. Huang, N. N., Van Loon, E. L., and Sheng, K. T.: The flora of the respiratory tract of patients with cystic fibrosis of the pancreas. J. Pediat. 59: 512 (1961).

16. Iacocca, V.F., Sibinga, M.S., and Barbero, G. J.: Respiratory tract bacteriology in cystic fibrosis. Amer. J. Dis. Child., 106: 115 (1963).

17. Kaiser, D., Pivetta, O. H., and Rennert, O. M.: Autosomal recessively inherited electrolyte excretory defect in the parotid of the "cribriform degeneration" mouse mutant. Possible analogy to cystic fibrosis. Life Sci., I5: 803 (1974).

18. Kass, E. H., Green, G. M., and Goldstein, E.: Mechanisms of antibacterial action in the respiratory system. Bactiol. Rev., 30: 488 (1966).

19. Lane, P. W., and Murphy, E. A.: Susceptibility to spontaneous pneumonitis in an inbred strain of mice. Genetics, 72: 451 (1972).

20. Laurenzi, G. A., Berman, L., First, M., and Kass, E. H.: A quantitative study of the deposition and clearance of bacteria in the murine lung. J. Clin. Invest., 43: 759 (1964).

21. Laurenzi, G. A., and Guarneri, J. J.: A study of the mechanisms of pulmonary resistance to infection: The relationship of bacterial clearance to ciliary and alveolar macrophage function. Amer. Rev. Resp. Dis., 93: 134 (1966).

22. Lawson, D.: Pseudomonas in cystic fibrosis. GAP Conference Report, National Cystic Fibrosis Research Foundation, Coronado, California, June 1974.

23. Lurie, M. B., Heppleston, A. G., Abramson, S., and Swartz, I. B.: An evaluation of the method of quantitative airborne infection and its use in the study of the pathogenesis of tuberculosis. Amer. Rev. Tuberc., 61: 765 (1950).

24. Middlebrook, G.: An apparatus for airborne infection of mice. Proc. Soc. Exp. Biol., 80: 105 (1952).

25. Myrvik, Q. N.: The lung as an organ of defense. GAP Conference Reports, National Cystic Fibrosis Research Foundation, Rougemont, North Carolina, November 1972.

26. Pivetta, O. H., Labal, M. L., and Sordelli, D. O.: Mouse sperm inhibition by sera from mice with human CF-like hereditary abnormalities. (In preparation.)

27. Ruppert, D., Jakab, G. J., Sylwester, D. L., and Green, G. M.: Sources of variance in the measurement of intrapulmonary killing of bacteria. J. Lab. Clin. Med., 87(3): 544 (1976).

28. Schwachman, H.: Changing concepts of CF. Hosp. Pract., 9: 143 (1974)

29. Difco Laboratories, Detroit, Mich.

30. Tryptic soy agar, Difco Laboratories, Detroit, Mich.

31. We are grateful to Dr. Nathan Kaliss and Dr. Earl L. Green from the Jackson Laboratory (Maine, USA), for their helpful advice and manuscript corrections. Our appreciation is also extended to Mrs. Susana Paz for secretarial assistance.

32. These studies were supported by grants from the National Cystic Fibrosis Research Foundation (USA).

33. Requests for reprints should be addressed to: Omar H. Pivetta, M.D., Centro de Genética Médica, Combate de los Pozos 2193, Buenos Aires (Argentina).

34. Received for publication August 23, 1976.

35. Accepted for publication March 9, 1977. 